\title{
FRASA PREPOSISI BAHASA KEDANG: ANALISIS X-BAR
}

\author{
Nurul Khasanah \\ Universitas Diponegoro Semarang \\ nurul11khasanah@gmail.com
}

\begin{abstract}
ABSTRAK
Jurnal ini menjelaskan struktur dan aturan pembentukan frasa preposisi dalam bahasa Kedang-NTT. Jurnal ini merupakan penelitian kualitatif dengan analisa konten bahasa. Data yang ada dimuat pada penelitian ini adalah data kedua sebagai pengembangan dari buku departemen pendidikan dan kebudayaan. Data dianalisis menggunakan teori sintak dengan menganalisa struktur menggunakan diagram pohon X-bar. Hasil pembahasan menunjukan bahwa terdapat empat bentuk frasa preposisi dalam bahasa kedang: (a) preposisi + kata benda, (b) preposisi + frasa nomina, (c) preposisi + frasa nomina + preposisi, (d) preposisi +kata benda + preposisi.
\end{abstract}

Kata kunci: Frasa, Preposisi, X-bar, Bahasa Kedang.

\section{ABSTRACT}

The structure and principles of how to form prepositional phrase in Kedang Language were investigated in this study. The study used qualitative method of content analysis as design of the research. Type of the data was secondary data from department of education and culture's book. The data were analyze using syntax theory of internal structure of tree diagram using Xbar. The result of the study showed the form of prepositional phrase in Kedang language consisted of four categories: (a) Preposition + Noun, (b) Preposition + Noun Phrase, (c) Preposition + Noun phrase + Preposition, (d) Preposition + Noun + Preposition.

Keywords: Phrase, Preposition, X-bar, Kedang Language.

\section{PENDAHULUAN}

Bahasa merupakan komponen penting dalam kehidupan manusia. Elemenlemen bahasa memiliki keterkaitan dan keterikatan dengan lisan ataupun tulisan. Hal tersebut membuat bahasa menjadi menarik untuk dikaji baik dari eksternal maupun internal. Sisi eksternal sebuah bahasa melihat bahasa dengan masyarakat dan kebudayaannya juga mengkaji masyarakat dengan variasi, seperti: psikolinguistik, sosiolinguitik, dialektologi, dll. Berbeda dengan kajian eksternal, mengkaji bahasa secara internal berarti meneliti bahasa dari dalam, kajian internal seperti fonologi, morfologi, maupun sintaks.

Semua bahasa menarik untuk dikaji karena memiliki keunikan pola masingmasing. Pernyataan Boaz mengenai bahasa menandakan bahwa tidak ada bahasa yang ideal didunia ini, semuanya bersifat relative, tergantung bagaimana kita mengkaji bahasa tersebut. Pada jurnal ini, penulis akan mengkaji bahasa kedang. Bahasa kedang (BK) merupakan bahasa yang dituturkan oleh masyarakat kedang, Kabupaten Lembata, Provinsi Nusa Tenggara Timur. Bahasa Kedang hanya dituturkan oleh dua kecamatan yang ada di Lembata, oleh karena itu bahasa ini angat jarang diketahui orang. Kebanyakan peneliti mengkaji kedang dari segi eksternalnya saja, bagaimana ritual-ritual dan pola pikir masyarakat di sana. 
Sedangkan, perkembangan bahasa kedang ditandai dengan bukti ortografis berupa kamus yang disususun oleh Robert H. Barnes dari Oxford tahun 2013.

Kridalaksana (1994:341) menjelaskan sintaksis sebagai kajian yang membahas tentang wacana, dialog, frasa, klausa, kalimat, kata, dan morfem. Mengkaji bahasa Kedang dari sisi semantik merupakan kajian internal yang sangat menarik karena bahasa ini dikenal dengan bahasa tanpa afiks atau zero afiks, namun memiliki pola frasa yang unik. Frasa dirasa sebagai suatu pola yang sedikit kompleks baik dari frasa tersebut ataupun keterikatannya dengan verba, kata sifat, dan kata keterangan. Dalam mengkontruksikan sebuah kalimat terjadi beberapa persamaan konsep dan beberapa frasa preposisi didalamnya. Frasa preposisi secara sintaksis menunjukan hubungan makna antara preposisi dan kelas kata yang berada dibelakangnya, seperti nomina, adjektiva, maupun adverbial.

Tulisan ini memaparkan frasa preposisional dalam bahasa Kedang. Struktur frasa akan dikaji menggunakan teori X-bar. Teori X-bar merupakan salah satu teori yang digagas oleh Chomsky yaitu tata bahasa generatif transformasi. Data dalam tulisan ini merupakan data sekunder dari buku yang dikeluarkan oleh departemen pendidikan dan kebudayaan pada tahun 1989 dengan judul Fonologi, Morfologi, dan Sintaksis bahasa Kedang. Data kemudian dipilih menggunakan teknik pilah catat oleh Sudaryanto (2015) Selain itu penulis juga menggunakan teknik ganti, sisip, perluas dan lesap. Penelitian ini bertujuan untuk menemukan pola pembentukan frasa preposisi (FP) dalam bahasa Kedang dan bagaimana kaidah X-bar mengatur pola pembentukan FP pada bahasa Kedang. Oleh karena itu aspek penting yang dibahas dalam jurnal ini adalah bagaimana pola pembentukan Frasa preposisi (FP) dalam bahasa kedang dan bagaimana kaidah X-bar mengatur pola FP dalam bahasa kedang.

Sebelumnya, penelitian mengenai X-bar dan pembentukan frasa pernah dilakukan oleh beberapa peneliti seperti Mulyadi pada tahun 2008 dengan tema struktur frasa adjektival dalam bahasa Indonesia. Hasil penelitian menunjukan pembentukan frasa dalam bahasa Indonesia umumnya terdiri dari +nucleus +complement +adjunct. Komplemen dan specifier mempunyai satu kategori sintaksis. Penelitian kedua dilakukan oleh Puti Novianti Aristia tahun 2017 tentang Frasa Adjektiva bahasa Jepang: Analisis X-bar dengan hasil terdapat unsur FA dalam bahasa Jepang dan setiap struktur memiliki Adj-i dan -na, diantaranya adjective + noun, adverb + adjective , noun + adjective, dan pronoun + adjective.

Kemudian penelitian tentang frasa juga dilakukan oleh Beratha (2012) dengan judul Frasa bahasa Bali Kuna dan perkembangnya ke bahasa Bali Modern. Hasil penelitiannya menunjukan adanya perubahan, perluasan tata bahasa pada frasa bahasa Bali Kuna ke dalam bahasa Bali modern. Selanjutnya, tesis yang ditulis oleh Muflikhatin (2017) dengan judul konstruksi verba serial tipe gerakan dalam bahasa Sunda: kajian tipologi dan X-bar. Hasil penelitiannya menjelaskan bahwa bahasa sunda memiliki konstruksi verba dengan struktur X-kom dan X-Adj sehingga dapat diketahui melalui teori X-bar. 
Penelitian kelima oleh Herliana (2018) dengan judul struktur Frase Nominal bahasa Mandarin berdasarkan teori X-bar. Hasil penelitian menunjukan bahwa FN dalam bahasa Mandarin terbentuk melalui $\mathrm{N}+\mathrm{N}, \operatorname{Adj}+\mathrm{N}, \mathrm{N}+$ Adj, Pron $+\mathrm{N}$, Adjunct + $\mathrm{N}+\mathrm{N}$. pada bahasa Mandarin, fungsi Sintak FN sebagai adjunct dan komplemen, yang mana komplemen bersifat wajib dan adjunct bersifat optional.

Berdasarkan lima penelitian yang telah disebutkan, peneliti belum menemukan adanya jurnal yang membahas tentang frasa preposisional (FP) dalam bahasa Kedang menggunakan analisis X-bar. Oleh karena itu, peneliti berharap kajian ini menjadi suatu kebaruan dalam kajian sintaksis.

Untuk menganalisa lebih lanjut mengenai keberadaan FP dalam bahasa Kedang, peneliti menggunakan kajian X-bar. Kajian ini merupakan kajian yang diperkenalkan oleh Chomsky melalui transformasi generative grammar. Teori ini menjelaskan secara detail unsur gramatika dalam suatu bahasa agar mendapatkan deskripsi gramatikal yang baik. Dalam teori X-bar satu inti leksikal mendominasi frasa artinya adalah inti dari FA adalah adjective, FP adalah preposisi, FN adalah nomina, dst.

Teori X-bar dijelaskan lebih lanjut oleh Haegeman (1992) dengan menggambarkan kaidah umum struktur frasa menurut teori X-bar:

1. $\mathrm{X}^{\prime \prime} \rightarrow$ Spec ; $\mathrm{X}^{\prime}$

2. $\mathrm{X}^{\prime} \rightarrow \mathrm{X}^{\prime}: \mathrm{YP}$

3. $X^{\prime} \rightarrow X$; YP

Deskripsi kaidah umum struktur frasa menurut teori X-bar:

1. X" adalah proyeksi maksimal suatu frasa, terdiri dari penentu (specifier) yang dikombinasikan dengan X' (proyeksi teratas/inti). Polanya sebagai berikut;

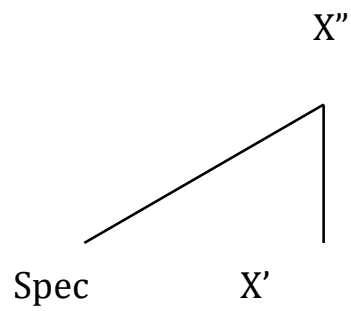

Diagram Pohon: 1

2. $X^{\prime}$ adalah proyeksi teratas/ inti yang berisi $X^{\prime}$ yang dikombinasikan dengan adjunct yaitu YP. Polanya adalah sebagai berikut: 


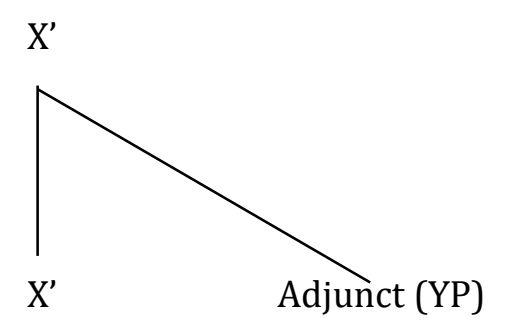

Diagram Pohon: 2

3. $\mathrm{X}^{\prime}$ adalah sebuah proyeksi yang terdiri dari kategori frasa leksikal (X) yang dikombinasikan dengan komplemen (YP). Polanya adalah sebagai berikut:

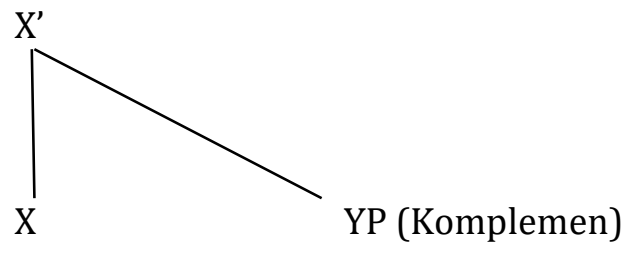

pohon: 3

Diagram

Secara umum diagram pohon dari keseluruhan struktur frase X-bar:

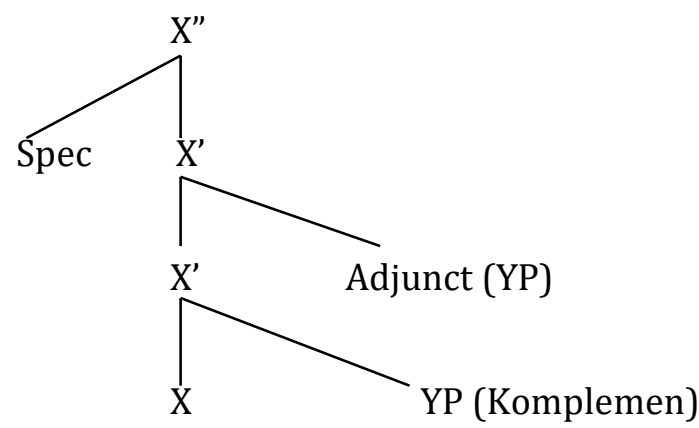

pohon: 4

Diagram

Dari diagram pohon di atas, dapat dijelaskan bahwa struktur frasa dibagi menjadi tiga cabang: pertama frasa inti digambarkan dengan $\mathrm{X}$, kedua, dua cabang yang disebut adjung dan komplemen berada di sisi sebelah kanan, ketiga frasa yang berada di sebelah kiri yang disebut specifier.

Diketahui adjunct merupakan komponen yang optional, jika pada kalimat sebelumnya telah muncul komplemen maka keberadaan adjunct tidak diperlukan lagi atau bisa dimasukan tetapi hanya sebagai keterangan tambahan saja.sedangkan posisi komplemen merupakan keterangan wajib pada sebuah kalimat.

\section{METODE PENELITIAN}

Penelitin ini menggunakan pendekatan kualitatif deskriptif dan analisis konten. Pendekatan yang dilakukan adalah dengan menganalisa frasa preposisi (FP) pada bahasa Kedang kemudian diuraikan menurut teori X-bar. Peneliti menggunakan pengetahuannya mengenai teori X-bar dan bahasa Kedang yang 
merupakan bahasa daerahnya. Data frasa merupakan data sekunder, kemudian peneliti juga memastikan kebenarannya dengan melakukan wawancara terhadap informan. Buku yag dijadikan acuan adalah buku fonologi, morfologi, dan sintaksis bahasa Kedang oleh Paulus Sawardo (1989). Dalam menganalisis data ada beberapa teknik yang diaplikasikan; reduksi data, penyajian data, verifikasi dan konklusi.

\section{HASIL DAN PEMBAHASAN}

\section{Pola Pembentukan Frasa Preposisi (FP) Bahasa Kedang}

Frasa preposisi bahasa Kedang menunjukan relasional atau sebagai penghubung dalam suatu kalimat. Jenis-jenis frasa preposisi dalam bahasa kedang diantaranya; (1) frasa preposisi menunjukan tempat, (2) frasa preposisi peralihan, (3) frasa preposisi arah, (4) frasa preposisi perihal/tujuan, (5) frasa preposisi persesuaian, (6) frasa preposisi syarat, (7) frasa preposisi perlawanan.

FP dalam bahasa kedang memiliki empat pola pembentukan, yaitu; (a) $\mathrm{P}+\mathrm{N}$, (b) $\mathrm{P}+\mathrm{FN}$, (c) $\mathrm{P}+\mathrm{FN}+\mathrm{P}$, (d) $\mathrm{P}+\mathrm{N}+\mathrm{P}$. contohnya pada frasa berikut ini:
(a) owe Larantuka
"dari Larantuka"
(b) owe leu' ude
"dari sebuah kampong"
(c) pan weta ude' laleng
"ke dalam sebuah rumah"
(d) mena ebang laleng
"dari dalam ebang (rumah kayu)"

\section{Kaidah X-bar Pada Frasa Preposisi Bahasa Kedang}

Kaidah penyusunan FP dalam bahasa Kedang menunjukan empat pola yang dapat diaplikasikan menggunakan teori $\mathrm{X}$-bar. Empat pola tersebut (a) $\mathrm{P}+\mathrm{N}$, (b) $\mathrm{P}+\mathrm{FN}$, (c) $\mathrm{P}+\mathrm{FN}+\mathrm{P}$, (d) $\mathrm{P}+\mathrm{N}+\mathrm{P}$ membentuk FP dalam bahasa Kedang. Terdapat dua pola urut yakni (a) dan (b) sedangkan dua pola menjelaskan adanya preposisi ganda yakni (c) dan (d). untuk mempertegas struktur FP dalam bahasa kedang maka dilakukanlah analisis menggunakan diagram pohon. Berikut merupakan diagram pohon teori X-bar dalam bahasa Kedang:

1. $\mathbf{P}+\mathbf{N}$ (Preposisi + Nomina)

$$
\begin{array}{lll}
\text { - } & \text { be'au "pada anjing" } & \text { (BK) (BI) } \\
\text { (Inti: Prep) (Komp: N) } & \\
\text { - } & \begin{array}{l}
\text { pan tuen "ke hutan" } \\
\text { (Inti: Prep) (Komp: N) }
\end{array} & \text { (BK) (BI) } \\
\text { - } & \begin{array}{l}
\text { Ewang wala "disana binatang" } \\
\text { (Inti: Prep) (Komp: N) }
\end{array} & \text { (BK) (BI) } \\
\text { - } & \text { Ole wata } \begin{array}{l}
\text { "di laut" } \\
\text { (inti: prep) (komp: N) }
\end{array} & \text { (BK) (BI) }
\end{array}
$$

Data di atas menunjukan ada dua tipe dalam frasa yaitu inti dan komplemen, inti dalam FP bahasa Kedang adalah

$$
\begin{array}{ll}
\text { /be'/pada/ } & / p a n / k e / \\
\text { /ewang/disana/ } & / \text { lole/di/ }
\end{array}
$$


Adapun struktur komplemen dalam FP bahasa Kedang adalah:

$$
\begin{array}{ll}
\text { /au'/anjing/ } & \text { /tuen/hutan/ } \\
\text { /wala/binatang/ } & \text { /wata/laut/ }
\end{array}
$$

Didalam struktur FP bahasa Kedang, inti berada di depan frasa mendahului komplemennya yang merupakan nomina. Jika digambarkan menggunakan X-bar; FP mrupakan proyeksi maksimal suatu frasa yang terdiri dari X' (inti) dan $\mathrm{N}$ sebagai komplemen.

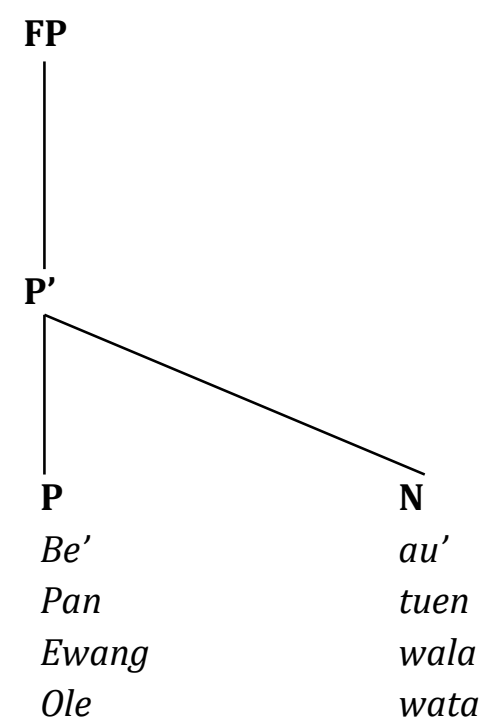

Diagram pohon: 5

\section{P +FN (Preposisi + Frasa Nomina)}

- Be' ana rutu ne' weta

di anak kecil nya rumah

"di rumahnya anak kecil"

(inti: prep) (komp: FN)

- Ewang au telu

disana anjing tiga

(inti: prep) (komp: FN)

- $\quad$ Ele are rian ude

Karena istri Satu

(inti: prep) (komp: FN) 
Berdasarkan data pada poin ke-dua, FP pada bahasa Kedang memiliki dua komposisi yaitu inti dan komplemen. Inti pada frasa di atas adalah;

$$
\begin{aligned}
& \text { /be'/di/ } \\
& \text { /ewang/disana/ } \\
& \text { /ele/karena/ }
\end{aligned}
$$

Adapun komplemen dalam FP bahasa Kedang:

/ana rutu ne'weta/ rumah anak kecil/

/au telu/tiga anjing/

/are rian ude/satu istri/

Didalam struktur FP bahasa kedang posisi inti berada di awal sebelum komplemen, jika digambarkan menggunakan X-bar sebagai berikut:

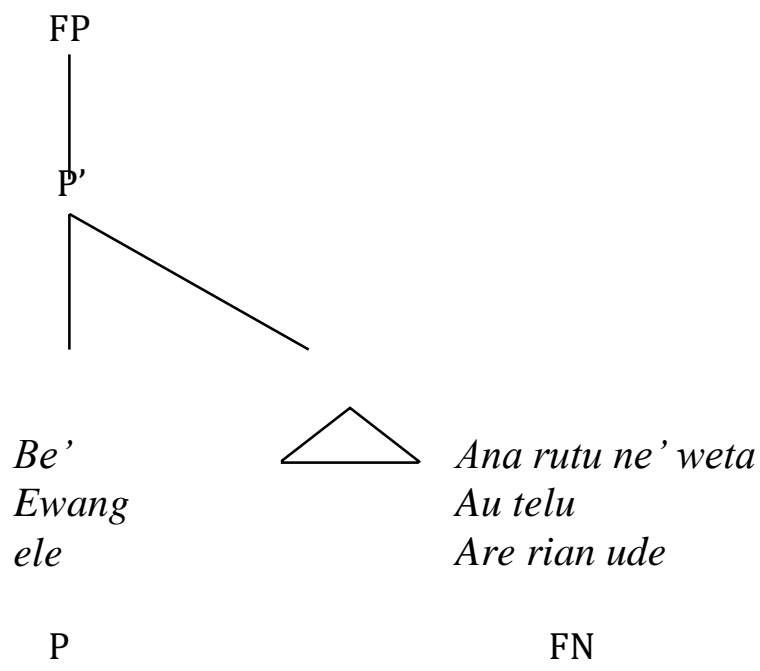

\section{Preposisi + Frasa Nomina + Preposisi}

- Be' anen abun laleng

di padi tangkai dalam

"didalam tangkai padi"

(inti: prep) (komp: FN) (Adjunct: prep)

- Be ula ne' nunu lalang

Di ular nya mulut dalam

"di dalam mulut ular"

(inti: prep) (komp: FN) (Adjunct: prep)

di kerbau nya hidung dalam

di dalam hidung kerbau 
(inti: prep) (komp: FN) (Adjunct: prep)

Berdasarkan frasa preposisi bahasa Kedang di atas, dapat dilihat bahwa terdapat dua preposisi yang muncul pada satu frasa. Preposisi pertama berfungsi sebagai inti frasa, kemudian preposisi yang kedua berada diakhir frasa dan berfungsi sebagai adjunct. Inti pada frasa di atas adalalah /be/di/

Adapun komplemen pada frasa di atas adalah;

/ anen abun/tangkai padi/

/ula ne' nunu/ mulut ular/

/arabau ne' ning/ hidung kerbau/

Adjunct yang ada pada frasa di atas adalah /laleng/dalam/.

Didalam struktur FP bahasa kedang tipe ketiga ini sedikit berbeda karena adanya double preposisi yang menjadi inti dan adjunct. Sedangkan komplemen berada diantara kedua preposisi tersebut. Teori X-bar yang menggambarkan pola frasa di atas adalah sebagai berikut:

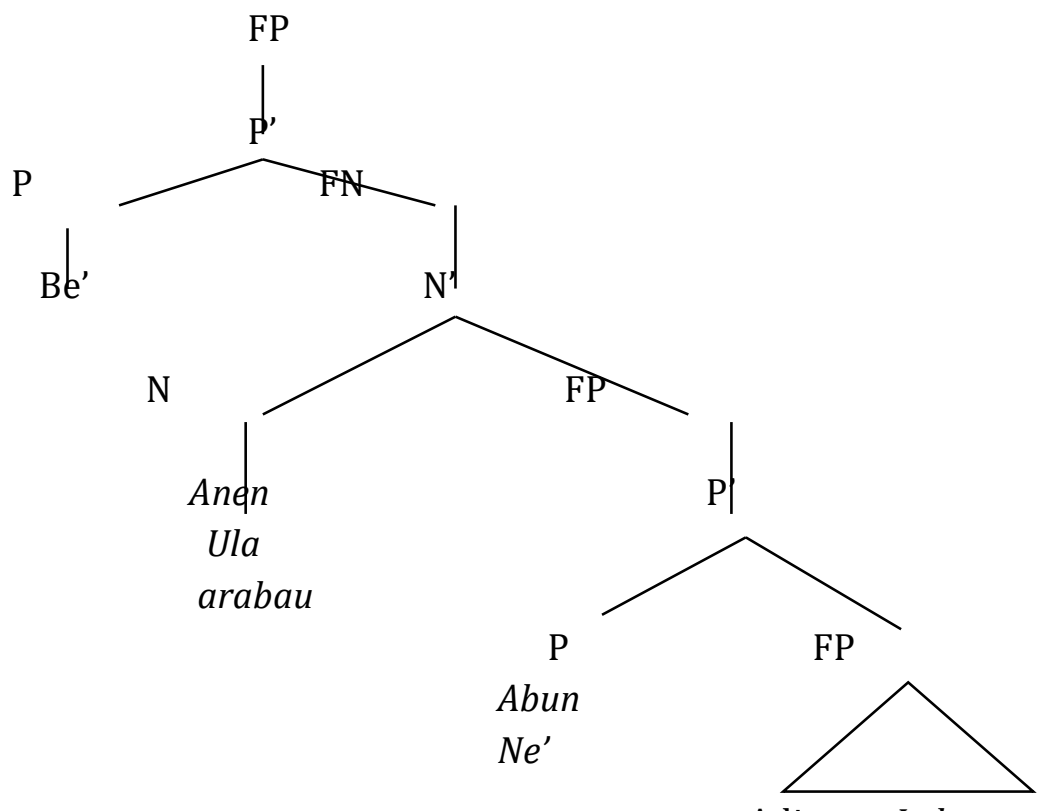

Diagram pohon: 7

Adjunct: Laleng

\section{Preposisi + Nomina + Preposisi}

- Pan tuan oyo

Ke laut dalam

"kedalam laut"

(inti: prep) (komp: FN) (Adjunct: prep) 
- Be ebang lolo

Di ebang atas

"di atas ebang"

(inti: prep) (komp: FN) (Adjunct: prep)

- Ole masingki obi

Di masjid belakang

"dibelakang masjid"

(inti: prep) (komp: FN) (Adjunct: prep)

Berdasarkan frasa preposisi bahasa Kedang di atas, dapat dilihat bahwa terdapat dua preposisi yang muncul pada satu frasa. Preposisi pertama berfungsi sebagai inti frasa, kemudian preposisi yang kedua berada diakhir frasa dan berfungsi sebagai adjunct. Inti pada frasa di atas adalah:

$$
\begin{aligned}
& \text { /pan/ke/ } \\
& \text { /be'/di/ } \\
& \text { /ole/di/ }
\end{aligned}
$$

Adapun komplemen pada frasa di atas adalah

$$
\begin{aligned}
& \text { /tuan/laut/ } \\
& \text { /ebang/rumah kayu/ } \\
& \text { /masingki/masjid/ }
\end{aligned}
$$

Adjunct yang ada pada frasa di atas adalah

$$
\begin{aligned}
& \text { /oyo/dalam/ } \\
& \text { /lolo/atas/ } \\
& \text { /obi/belakang/ }
\end{aligned}
$$

Di dalam struktur FP bahasa Kedang tipe ketiga ini sedikit berbeda karena adanya preposisi ganda yang menjadi inti dan adjungt. Sedangkan komplemen berada diantara kedua preposisi tersebut. Teori X-bar yang menggambarkan pola frasa di atas adalah sebagai berikut: 


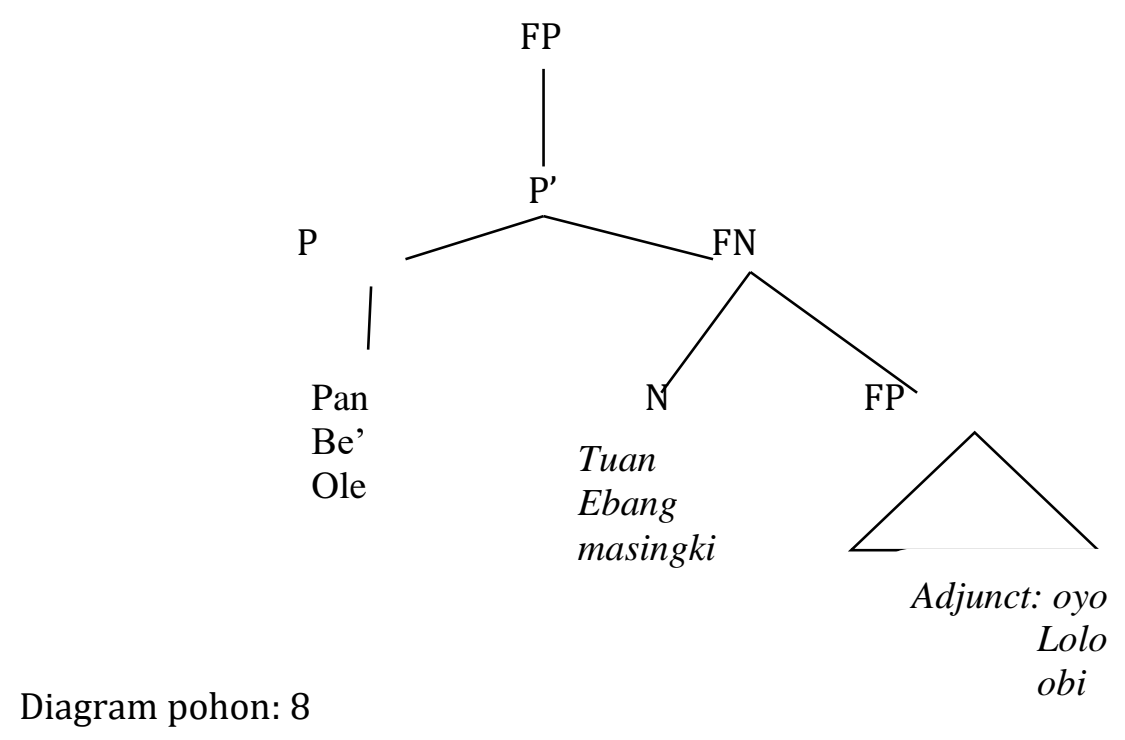

\section{SIMPULAN}

Penelitian ini mendeskripsikan frasa preposisi dalam bahasa Kedang. Aspek yang dibahas dalam jurnal ini adalah pola pembentukan frasa dan kaidah X-bar untuk menganalisa frasa preposisi tersebut. Dalam bahasa Kedang pola FB dikelompokan menjadi empat kategori, diantaranya; (a) $\mathrm{P}+\mathrm{N}$, (b) $\mathrm{P}+\mathrm{FN}$, (c) $\mathrm{P}+\mathrm{FN}+\mathrm{P}$, (d) $\mathrm{P}+\mathrm{N}+\mathrm{P}$.

Peneliti berharap dikemudian hari akan melanjutkan penelitian mengenai frasa-frasa lainnya dalam Bahasa kedang.

\section{DAFTAR PUSTAKA}

Aristia, P. N. (2017). Frasa Adjektiva Bahasa Jepang: Analisis X-bar. LINGUA, 295308.

Beratha, N. L. (2012). Frasa Bahasa Bali Kuna dan Perkembangannya ke Bahasa Bali Modern. Jurnal Kajian Bali, 69-86.

Chaer, A. (2007). Linguistik Umum. Jakarta: Rineka Cipta.

Haegeman, L. (1992). Introduction to Govermant and Binding Theory. Cambridge: Cambridge University press.

Herliana, M. (2018). Struktur Frase Nominal Bahasa Mandarin Berdasarkan Teori Xbar. Jurnal Cakrawala Mandarin , 46-57. 
Kridalaksana, H. (2007). Kamus Linguistik . Jakarta: Gramedia.

Muflikhatin, I. (2017). Konstruksi Verba serial tipe gerakan dalam bahasa sunda: kajian tipologi dan X-bar. SEMARANG: UNDIP.

Mulyadi. (2008). Struktur Frasa Adjektival dalam Bahasa Indonesia. Jurnal Ilmiah Bahasa dan Sastra, 28-30.

Paulus Sawardo, N. H. (1989). Fonologi, Morfologi, dan Sintaksis bahasa Kedang. Jakarta: Kementrian Pendidikan Nasional.

Sudaryanto. (2015). metode dan aneka teknik analisis bahasa. Yogyakarta: Sanata Dharma University Press. 